Carbido Complexes

DOI: 10.1002 /ange.200601652

\section{Carbon-Carbon Bond Formation at a Neutral Terminal Carbido Ligand: Generation of Cyclopropenylidene and Vinylidene Complexes**}

\author{
Stephen R. Caskey, Michael H. Stewart, \\ Marc J. A. Johnson, * and Jeff W. Kampf
}

Olefin metathesis is an important tool for organic and polymer synthesis. ${ }^{[1]}$ However, some key functional groups are not tolerated even by Ru-based catalysts. ${ }^{[2]}$ We recently showed that vinyl esters can deactivate $[\mathrm{Ru}(\mathrm{CHPh})$ $\left.\left(\mathrm{PCy}_{3}\right)_{2} \mathrm{Cl}_{2}\right] \quad(\mathbf{1})^{[3]}$ by quantitative formation of $[\mathrm{Ru}(\mathrm{C})-$ $\left.\left(\mathrm{PCy}_{3}\right)_{2} \mathrm{Cl}_{2}\right](\mathbf{2})^{[4,5]}$ A rare neutral terminal carbido complex,${ }^{[4-7]} \mathbf{2}$ is surprisingly stable and has few reported reactions. ${ }^{[5-7]}$ However, protonation of $\mathbf{2}$ by strong acid yields catalysts that rapidly initiate olefin metathesis. ${ }^{[7]}$ Thus, $\mathbf{2}$ is both a precursor to and a decomposition product of olefin metathesis catalysts. We see $\mathbf{2}$ as a potential source of a $\mathrm{C}_{1}$ fragment. Accordingly, we describe herein the first $\mathrm{C}-\mathrm{C}$ bond-forming reaction of this unusual compound.

The terminal carbido ligand in $\mathbf{2}$ is a poor nucleophile, as shown by its failure to react with $\mathrm{MeI}, \mathrm{MeCOCl}$, and $\mathrm{PhCH}_{2} \mathrm{Br}$. Although 2 does not react with a variety of alkenes and alkynes (see the Supporting Information), it reacts cleanly with $\mathrm{MeO}_{2} \mathrm{CC} \equiv \mathrm{CCO}_{2} \mathrm{Me}$ (dimethyl acetylenedicarboxylate, DMAD) over $4 \mathrm{~h}$ in $\mathrm{C}_{6} \mathrm{H}_{6}$. A new blue-purple complex, $\mathbf{3}$, is formed as the carbido signal for $\mathbf{2}\left({ }^{13} \mathrm{C} \mathrm{NMR}\right.$ : $\delta=471.8 \mathrm{ppm}$ ) is replaced by a new signal at $\delta=195.7 \mathrm{ppm}$. The ${ }^{1} \mathrm{H}$ NMR spectrum evinces formation of a 1:1 adduct of 2 with DMAD. Formation of the cyclopropenylidene complex $\left[\mathrm{Ru}\left\{=\mathrm{CC}_{2}\left(\mathrm{CO}_{2} \mathrm{Me}\right)_{2}\right\}\left(\mathrm{PCy}_{3}\right)_{2} \mathrm{Cl}_{2}\right]$ (Scheme 1) accounts for these observations. Several cyclopropenylidene complexes exist. Unlike 3, however, the cyclopropenylidene units in these complexes are substituted by phenyl or electrondonating groups. ${ }^{[8-23]} \quad\left[\mathrm{Ru}(\mathrm{C})\left(\mathrm{H}_{2} \mathrm{IMes}\right)\left(\mathrm{PCy}_{3}\right) \mathrm{Cl}_{2}\right] \quad$ (4; $\mathrm{H}_{2} \mathrm{IMes}=4,5$-dihydro-1,3-bis(mesityl)imidazol-2-ylidene) reacts similarly with DMAD, but the reaction is not clean since the product reacts further with DMAD before all of $\mathbf{4}$

[*] S. R. Caskey, M. H. Stewart, Prof. M. J. A. Johnson, Dr. J. W. Kampf Department of Chemistry

University of Michigan

930 North University Avenue

Ann Arbor, MI 48109-1055 (USA)

Fax: $(+1)$ 734-647-4865

E-mail:mjaj@umich.edu

[**] This report is based upon work supported by the National Science Foundation under grant number CHE-0449459. We thank the Research Corporation, the University of Michigan, and the Camille and Henry Dreyfus Foundation for support. S.R.C. thanks the University of Michigan Chemistry Department for Margaret and Herman Sokol and Robert W. Parry Fellowships.

$\Rightarrow$ Sup Supporting information for this article (including complete experimental details for new reactions) is available on the WWW under http://www.angewandte.org or from the author.

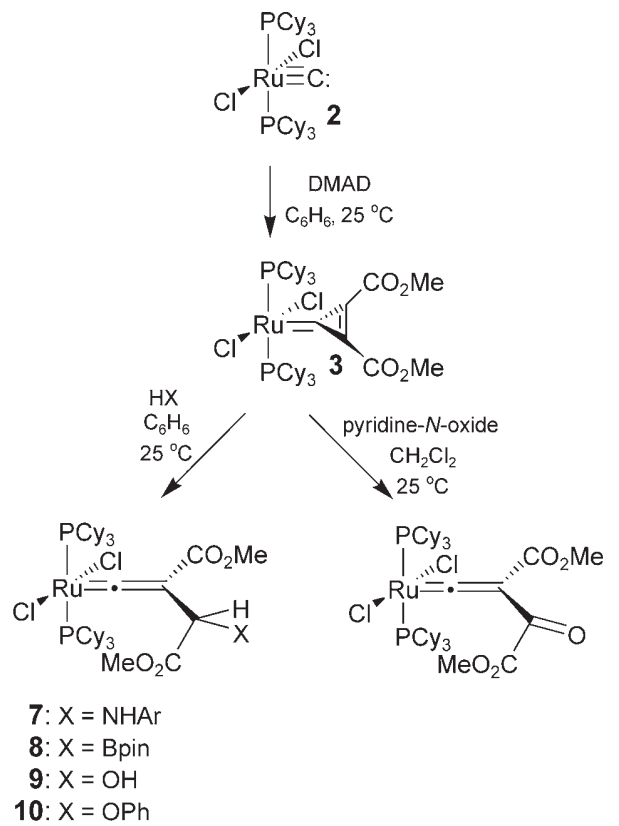

Scheme 1. Formation of 3 and ring-opening reactions. $\mathrm{HBpin}=$ pinacolborane, $\mathrm{Ar}=3,5-\mathrm{Me}_{2} \mathrm{C}_{6} \mathrm{H}_{3}$.

has been consumed. However, 4 reacts more cleanly with $\mathrm{HC} \equiv \mathrm{CCO}_{2} \mathrm{Me}$ (see the Supporting Information).

Single-crystal X-ray diffraction confirmed the structure of 3. ${ }^{[24]}$ Figure 1 depicts a thermal ellipsoid plot of one of the two chemically equivalent but crystallographically independent molecules of $\mathbf{3}$ in the crystal. The data establish the expected connectivity in $\mathbf{3}$, but the large uncertainty associated with the $\mathrm{Ru}=\mathrm{C}$ bond length of $1.846(10) \AA$ precludes comparison with those in related alkylidene complexes. The cyclopropenylidene ring lies in the $\mathrm{Cl}-\mathrm{Ru}-\mathrm{Cl}$ plane. The structure shows significant bond localization in the cyclopropenylidene fragment. These distances closely resemble those observed in free

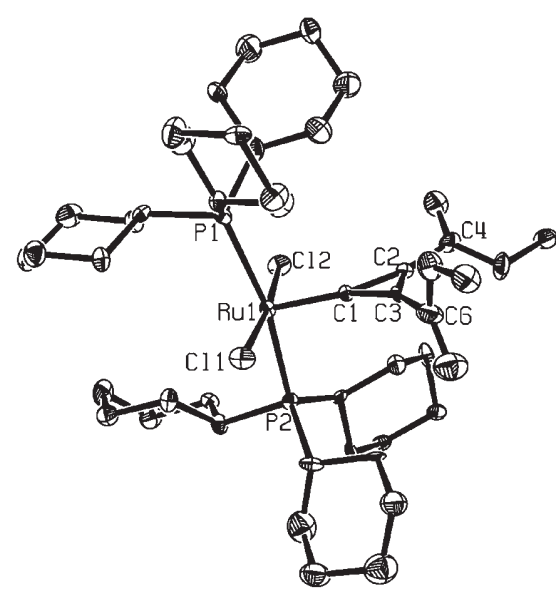

Figure 1. X-ray crystal structure of 3 (50\% thermal ellipsoids). Selected bond lengths $[\AA]$ and angles [ $\left.{ }^{\circ}\right]$ : Ru1-C1 1.846(10), Ru1-Cl1 2.389(3), Ru1-Cl2 2.402(3), Ru1-P1 2.407(3), Ru1-P2 2.390(3), C1-C2 1.410(13), C1-C3 1.425(14), C2-C3 1.300(14); C1-Ru1-Cl1 91.6(3); C1-Ru1-Cl2, 95.3(3), C1-Ru1-P1 97.0(3), C1-Ru1-P2 95.8(3), C2-C1-C3 54.6(7), C1C2-C3 63.3(7), C1-C3-C2 62.1(7). 
$\mathrm{C}_{3}\left(\mathrm{NiPr}_{2}\right)_{2} \quad(\mathbf{5})^{[25]}$ and in other cyclopropenylidene complexes. ${ }^{[9,14-23]}$

The formation of $\mathbf{3}$ from $\mathbf{2}$ is interesting because the cyclopropylidene complex $\quad\left[\mathrm{Ru}\left\{=\mathrm{CC}_{2} \mathrm{H}_{2}\left(\mathrm{CO}_{2} \mathrm{Me}\right)_{2}\right\}\right.$ $\left.\left(\mathrm{PCy}_{3}\right)_{2} \mathrm{Cl}_{2}\right](\mathbf{6})$ is not observed as an intermediate when $\mathbf{2}$ is formed from 1 by reaction with Feist's ester. ${ }^{[4]}$ Addition of 2 equivalents or less of $\mathrm{PCy}_{3}$ to $\left[\mathrm{Ru}\left\{=\mathrm{CC}_{2} \mathrm{H}_{2}\left(\mathrm{CO}_{2} \mathrm{Me}\right)_{2}\right\}\right.$ $\left(\mathrm{PPh}_{3}\right)_{2} \mathrm{Cl}_{2}$ ] similarly yields 2 . In this case, too, 6 is not seen. ${ }^{[6]}$

The ${ }^{13} \mathrm{C}$ NMR shifts of the ring atoms in $\mathbf{3}, 195.7$ and 162.2 ppm, closely resemble those observed for $\mathbf{5}^{[25]}$ but less so other cyclopropenylidene complexes, for which some cyclopropenium character is often invoked. ${ }^{[14-23]}$ Unlike $\mathbf{1}, \mathbf{3}$ does not react appreciably with common olefins or alkynes, although under some conditions small amounts of $\mathbf{2}$ are formed, suggesting reversibility of the $\mathbf{2} \rightarrow \mathbf{3}$ transformation (see the Supporting Information). However, several reagents effect 1,1-addition of $\mathrm{HX}$ to the ring to form vinylidene complexes 7-10; reaction with pyridine- $N$-oxide similarly yields 11 (Scheme 1). Cyclopropenium character could account for the observed reactivity, as all the reagents shown can act first as nucleophiles; however, there may be other explanations.

The structure of one vinylidene complex, $[\mathrm{Ru}\{=\mathrm{C}=\mathrm{C}$ $\left.\left.\left(\mathrm{CO}_{2} \mathrm{Me}\right) \mathrm{CH}(\mathrm{NHAr}) \mathrm{CO}_{2} \mathrm{Me}\right\}\left(\mathrm{PCy}_{3}\right)_{2} \mathrm{Cl}_{2}\right] \quad$ (7, $\mathrm{Ar}=3,5-$ $\mathrm{Me}_{2} \mathrm{C}_{6} \mathrm{H}_{3}$ ), was determined by single-crystal X-ray diffraction. ${ }^{[26]}$ The vinylidene unit is apical in square-pyramidal 7 (Figure 2).

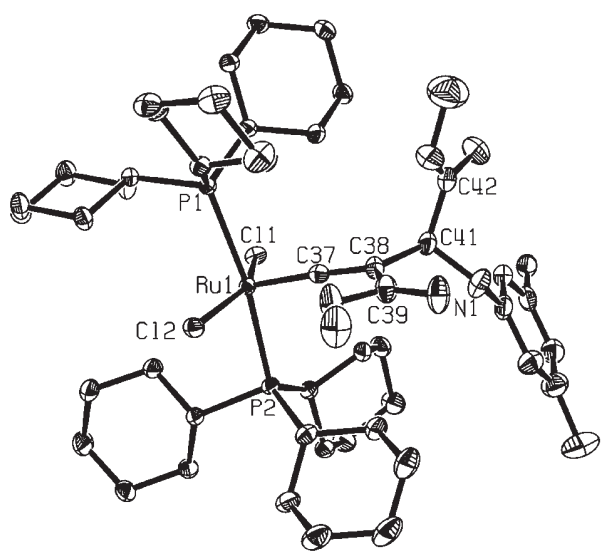

Figure 2. X-ray crystal structure of 7 (50\% thermal ellipsoids). Selected bond lengths $[\AA]$ and angles $\left[{ }^{\circ}\right]$ : Ru1-C37 1.7458(17), Ru1-Cl1 2.3441 (4), Ru1-Cl2 2.3454(4), Ru1-P1 2.4405(4), Ru1-P2 2.4098(4), C37-C38 1.344(2); C37-Ru1-Cl1 105.16(5), C37-Ru1-Cl2 100.68(5), C37Ru1-P1 95.78(5), C37-Ru1-P2 93.39(5), Ru1-C37-C38 176.16(14), C37C38-C39 118.76(16), C37-C38-C41 121.94(16), C39-C38-C41 $119.23(15)$.

Ruthenium vinylidenes are useful as catalysts and catalyst precursors for olefin metathesis, alkyne dimerization, and other reactions. ${ }^{[27,28]}$ Like the "parent" vinylidene complex $\left[\mathrm{Ru}\left(=\mathrm{C}=\mathrm{CH}_{2}\right)\left(\mathrm{PCy}_{3}\right)_{2} \mathrm{Cl}_{2}\right],{ }^{[3]} \mathbf{7 - 1 1}$ do not catalyze the ringclosing metathesis of diethyl diallylmalonate, but they do polymerize norbornene.

In summary, terminal carbido complex $\mathbf{2}$ undergoes $[2+1]$ addition with DMAD to yield the cyclopropenylidene complex 3. Complex 4 reacts similarly with $\mathrm{HC}=\mathrm{CCO}_{2} \mathrm{Me}$ in the first $\mathrm{C}-\mathrm{C}$ bond-forming reactions reported for neutral terminal carbido complexes. Protic reagents $\mathrm{HX}(\mathrm{X}=\mathrm{OH}$, $\left.\mathrm{OPh}, \mathrm{NH}\left(3,5-\mathrm{Me}_{2}\right) \mathrm{C}_{6} \mathrm{H}_{3}\right)$ as well as pinacolborane add in a 1,1 manner to one of the distal ring $\mathrm{C}$ atoms in $\mathbf{3}$, forming vinylidene complexes 7-11 in high yield. We are currently exploring the reactivity of $\mathbf{7 - 1 1}$ as well as seeking a means of regenerating a metathesis-active alkylidene complex or the carbide complexes 2 and $\mathbf{4}$.

Received: April 26, 2006

Revised: July 19, 2006

Published online: October 17, 2006

Keywords: carbides · cycloaddition .

cyclopropenylidene ligands $\cdot$ ruthenium $\cdot$ vinylidene ligands

[1] R. H. Grubbs, Handbook of Metathesis, Wiley-VCH, Weinheim, 2003.

[2] C. Morrill, R. H. Grubbs, J. Org. Chem. 2003, 68, 6031.

[3] P. Schwab, R. H. Grubbs, J. W. Ziller, J. Am. Chem. Soc. 1996, $118,100$.

[4] R. G. Carlson, M. A. Gile, J. A. Heppert, M. H. Mason, D. R. Powell, D. Vander Velde, J. M. Vilain, J. Am. Chem. Soc. 2002, 124, 1580.

[5] S. R. Caskey, M. H. Stewart, J. E. Kivela, J. R. Sootsman, M. J. A. Johnson, J. W. Kampf, J. Am. Chem. Soc. 2005, 127, 16750.

[6] A. Hejl, T. M. Trnka, M. W. Day, R. H. Grubbs, Chem. Commun. 2002, 2524

[7] P. E. Romero, W. E. Piers, R. McDonald, Angew. Chem. 2004, 116, 6287; Angew. Chem. Int. Ed. 2004, 43, 6161.

[8] K. Öfele, Angew. Chem. 1968, 80, 1032; Angew. Chem. Int. Ed. Engl. 1968, 7, 950.

[9] G. Huttner, S. Schelle, O. S. Mills, Angew. Chem. 1969, 81, 536; Angew. Chem. Int. Ed. Engl. 1969, 8, 515.

[10] K. Öfele, J. Organomet. Chem. 1970, 22, C9.

[11] C. W. Rees, E. V. Angerer, J. Chem. Soc. Chem. Commun. 1972, 420.

[12] R. Gompper, E. Bartmann, Angew. Chem. 1978, 90, 490; Angew. Chem. Int. Ed. Engl. 1978, 17, 456.

[13] R. Weiss, C. Priesner, Angew. Chem. 1978, 90, 491; Angew. Chem. Int. Ed. Engl. 1978, 17, 457.

[14] R. D. Wilson, Y. Kamitori, H. Ogoshi, Z. I. Yoshida, J. A. Ibers, J. Organomet. Chem. 1979, 173, 199.

[15] U. Kirchgaessner, U. Schubert, Organometallics 1988, 7, 784.

[16] K. N. Juneau, L. S. Hegedus, F. W. Roepke, J. Am. Chem. Soc. 1989, 111,4762 .

[17] P. M. Fritz, J. Breimair, B. Wagner, W. Beck, J. Organomet. Chem. 1992, 426, 343.

[18] J. Schubert, S. Mock, U. Schubert, Chem. Ber. 1993, 126, 657.

[19] M. Tamm, A. Grzegorzewski, F. E. Hahn, J. Organomet. Chem. 1995, 501, 309.

[20] M. S. Morton, J. P. Selegue, A. Carrillo, Organometallics 1996, $15,4664$.

[21] M. Lutz, M. Haukka, T. A. Pakkanen, L. H. Gade, Organometallics 2001, 20, 2631.

[22] A. de Meijere, S. Müller, T. Labahn, J. Organomet. Chem. 2001, $617,318$.

[23] B. Fuss, M. Dede, B. Weibert, H. Fischer, Organometallics 2002, $21,4425$.

[24] Crystal data for 3.1.5 $\mathrm{CH}_{2} \mathrm{Cl}_{2}: \mathrm{C}_{44.50} \mathrm{H}_{75} \mathrm{Cl}_{5} \mathrm{O}_{4} \mathrm{P}_{2} \mathrm{Ru}$, monoclinic, $P 2_{1} / c, \quad a=11.926(2), \quad b=18.555(3), \quad c=45.638(8) \AA, \quad \beta=$ $96.800(3)^{\circ}, V=10028(3) \AA^{3}, Z=8, \rho_{\text {calcd }}=1.344 \mathrm{~g} \mathrm{~cm}^{-3}, \mathrm{Mo}_{\mathrm{K} \alpha}$ radiation, $\lambda=0.71073 \AA, T=123(2) \mathrm{K}, 43778$ measured reflec- 


\section{Zuschriften}

tions, 8524 unique $\left(R_{\text {int }}=0.1875\right), 4942$ reflections with $I_{\text {net }}>$ $2.0\left(I_{\text {net }}\right), \mu=0.681 \mathrm{~mm}^{-1}, \mathrm{~min} / \mathrm{max}$ transmission $=0.8758$ and $0.9412, R 1(I>2 \sigma)=0.0775, w R 2=0.1954, \mathrm{GoF}=1.066$, no. of parameters $=1056$, final difference map within 1.008 and -1.258 e $\AA^{-3}$. CCDC-604841 $\left(3 \cdot 1.5 \mathrm{CH}_{2} \mathrm{Cl}_{2}\right)$ contains the supplementary crystallographic data for this paper. These data can be obtained free of charge from The Cambridge Crystallographic Data Centre via www.ccdc.cam.ac.uk/data_request/cif.

[25] V. Lavallo, Y. Canac, B. Donnadieu, W. W. Schoeller, G. Bertrand, Science 2006, 312, 722.

[26] Crystal data for 7: $\mathrm{C}_{51} \mathrm{H}_{83} \mathrm{Cl}_{2} \mathrm{NO}_{4} \mathrm{P}_{2} \mathrm{Ru}$, monoclinic, $P 2_{1} / c, a=$ $15.5355(8), \quad b=18.9133(10), c=17.5169(9) \AA, \quad \beta=97.403(1)^{\circ}$ $V=5104.0(5) \AA^{3}, \mathrm{Z}=4, \rho_{\text {calcd }}=1.312 \mathrm{~g} \mathrm{~cm}^{-3}, \mathrm{Mo}_{\mathrm{K} \alpha}$ radiation, $\lambda=0.71073 \AA, T=123(2) \mathrm{K}, 101108$ measured reflections, 12702 unique $\left(R_{\mathrm{int}}=0.0321\right), 11419$ reflections with $I_{\text {net }}>2.0$ $\left(I_{\text {net }}\right), \quad \mu=0.518 \mathrm{~mm}^{-1}, \quad \min / \max$ transmission $=0.8197$ and $0.8602, R 1(I>2 \sigma)=0.0295, w R 2=0.0740, \mathrm{GoF}=1.059$, no. of parameters $=554$, final difference map within 0.885 and -0.727 e $\AA^{-3}$. CCDC-604842 (7) contains the supplementary crystallographic data for this paper. Data can be obtained as in Reference [24].

[27] C. Bruneau, P. H. Dixneuf, Angew. Chem. 2006, 118, 2232; Angew. Chem. Int. Ed. 2006, 45, 2176.

[28] H. Katayama, F. Ozawa, Coord. Chem. Rev. 2004, 248, 1703. 